\title{
How do ICT project managers manage project knowledge in the public sector? An empirical enquiry from the Victorian Public Sector in Australia
}

\author{
Yakub Karagoz \\ Victoria University \\ yakub.karagoz@live.vu.edu.au
}

Axel Korthaus

Victoria University

Naomi Augar
RMIT University

\section{Abstract}

Projects are temporal organisation forms that are highly knowledge-intensive and play an important role in modern public (and private) sector organisations. The effective and efficient creation, dissemination, application and conservation of relevant knowledge are a critical success factor in the management of projects. Yet, project management (PM) and knowledge management (KM) are two distinct disciplines. This paper explores the relationship between $\mathrm{PM}$ and KM by analysing the literature at the intersection of those disciplines and presenting the empirical results of a case study of the Victorian Public Sector (VPS) in Australia. A series of 14 interviews were conducted to explore how ICT project managers manage project knowledge across the departments of the VPS. Findings show a strong preference among the participants for informal, face-to-face interactions and agile approaches to facilitate knowledge transfer and creation in ICT project environments.

Keywords: ICT; project manager; project management; projects; knowledge; knowledge management; public sector; case study.

\section{Introduction}

Within academic and community circles, project management (PM) is understood to be a sub discipline or a specialised branch of management that has progressed to control modern day business ventures (Karagoz et al et al., 2014). PM, according to the Project Management Institute "...is the application of knowledge, skills, tools, and techniques to project activities to meet the project requirements" (PMI, 2013a, p. 5). Put simply, a project is motivated by a unique idea to introduce change, whereas PM is the consulting aid to realise its purpose.

Turner (2009) refers to projects as temporary organisations. When a business endeavours to accomplish a vision of its future state, it creates a new organisation with a temporary existence, disbanded once the objectives are achieved. In many instances, information and communications technology (ICT) initiatives are implemented via projects (Cadle \& Yeates, 2004) and effective management of such projects is imperative in today's turbulent and competitive climate. While the importance of investing in ICTs and their applications cannot be ignored, there is, however, high level of interest and concern when it comes to investing in such endeavours, particularly those funded by the taxpayer. Rosacker and Rosacker (2010) postulate that “...IT projects are far too often...wasteful, inefficient, mismanaged, expensive and behind schedule" (p. 578). Past and present projects across the Australian Public Sector have resulted in similar outcomes (Brouwer, 2011).

$\mathrm{PM}$ is innately a knowledge-intensive activity and there is growing interest in how knowledge management (KM) integrates with PM practices. Like the terms project and PM, there is no unified or agreed definition of KM (Gasik, 2011). However, scholars do tend to agree it adds value to the organisation, for example, competitive advantage (Argote \& Ingram, 2000; PMI, 2015). 
Sarayreh et al. (2012) suggest that KM “... is about trying to harvest all the insights and experience that go into making an organisation function" (p. 45) while Abdul Rahman et al. (2008) conclude that KM is a strategy to identify, create, acquire, transfer, share and exploit knowledge. Gasik (2011) separated the definition of KM across two camps, "...the first focuses on processing the single knowledge element and enumerates functions of its life cycle" (p. 23) and the second camp "...focuses on the whole knowledge possessed by individuals and organisations and the benefits of its application" (p. 24). This looks at how to generate and leverage knowledge that creates business value and sustains competitive advantage (Zhang, 2007).

Research from the turn of the 21st century revealed considerable efforts to shed light on and promote the importance of KM in Australia. For example, in 2005, the Australian Standard (AS5037-2005) for KM was published offering a framework that was flexible for “...designing, planning, implementing and assessing policies and initiatives to improve knowledge management in an organisation" (Linger et al., 2007, p. 6). The standard offers guidance for organisations and provides methodologies and tools to assess their readiness to adopt KM concepts.

The academic community is becoming increasingly interested in the study of knowledge sharing (Boateng \& Agyemang, 2014; Mansingh et al., 2014; Sandhu et al., 2011; Seba et al., 2012; Yao et al., 2007; Yusof et al., 2012). In addition, there appears to be demonstrable evidence linking effective KM and in particular, knowledge sharing activities to creativity (Wang \& Noe, 2010), critical decision-making (Mohammed \& Jalal, 2011) and importantly, success in project delivery (Ismail et al., 2009).

However, the majority of KM and knowledge sharing studies as they relate to PM are concerned with private enterprises and to date, there is a lack of research undertaken towards understanding KM in project environments across the public sector (Amayah, 2013). There is also relatively limited scholarly analysis geared towards examining and providing a descriptive analysis on how the project manager manages project knowledge. Therefore, this paper contributes to the literature by examining how ICT project managers manage project knowledge in the Victorian Public Sector in Australia.

This paper is structured as follows. The next section reviews literature related to KM and PM in the global and Australian context and examines work to date that focuses on knowledge and the project manager. This is followed by the methodology and presentation of the results of the research. The paper concludes with a discussion and recommendations for further work.

\section{Background}

This section examines knowledge management in Australia and in project environments. It highlights KM models that have influenced this research and explores the relationship between knowledge and the project manager.

\subsection{Knowledge management in Australia}

Coyte et al. (2012) examined the methods adopted to control the management of knowledge resources in small and medium enterprises (SMEs) in Australia. The authors found that certain mechanisms were in place, which governed the strategisation and management of knowledge resources. These included informal, intensive dialogue based processes, structured by an overriding management philosophy. Various other authors have examined KM within the context of Australia including the dairy industry (Soliman, 2000), law firms (Khandelwal \& Gottschalk, 2003), intellectual capital (Zhou \& Fink, 2003), construction companies (Maqsood et al., 2006), software development (Aurum et al., 2008) and not-for-profit organisations (Downes, 2014).

Interestingly, Zhou (2004) compared managers' perceptions between private and public sectors in Australia to develop a greater understanding of current KM practices. The results showed that public sector respondents in Australia had a less developed understanding of KM 
and intellectual capital when compared to the respondents from private sectors. At the public sector level, Zhou (2004) highlighted that respondents had little understanding of KM practices and were unsure about the organisational structure. Further, KM initiatives were often ignored at the top level. Zhou (2004) also noted that very few processes were in place with no incentive and reward measures established, concluding that the context of the organisation in which they work heavily impacts managers' perceptions of KM.

\subsection{Knowledge management models}

According to Cong and Pandya (2003), "the terms 'information' and 'data' are often used interchangeably with the term "knowledge"' (p. 26), whilst in fact these concepts have different meanings. Understanding these differences is important if the aim is to manage knowledge successfully. Data is generally considered as raw facts such as a set of abstract numbers or values. Information is data put in a given context, endowed with meaning and purpose (Wallace, 2007), which in turn supports decision making (Cong \& Pandya, 2003). Knowledge “...embodies cognition, insight, erudition” (Blumentritt \& Johnston, 1999, p. 291) and by extension, enables efficient management of data and information (Grant \& Grant, 2008).

$\mathrm{KM}$ is often seen as an organisation's ability to learn or handle knowledge processes (process view) or its ability to handle knowledge (product view) (Maier et al., 2005). From a process view, at least four core processes of $\mathrm{KM}$, notably creation, storage and retrieval, distribution/transfer and application of knowledge, are present in nearly all definitions of KM (Alavi \& Leidner, 2001). This is sometimes referred to as the KM life cycle (Dalkir, 2005). Whilst very similar in essence, various authors describe different KM life cycles, often built on existing frameworks (Sağsan, 2006). As an example, the KM life cycle developed by Evans et al. (2014) has been derived from the model described in Evans and Ali (2013) and contains the seven phases: identify, store, share, use, learn, improve and create. Similarly, Sağsan (2006) developed a comprehensive model consisting of only five sequential steps. From the KM literature, it is apparent that knowledge transfer and knowledge sharing have been used synonymously (Renzl, 2006) and are recognised to have different meaning to different authors (Paulin \& Suneson, 2015). For the purposes of this research, knowledge sharing is "the exchange of knowledge between and among individuals" (Schwartz, 2005, p. 542) and knowledge transfer is the transmission of information from source to recipient (Renzl, 2006).

A seminal work in KM-related literature, which has become the cornerstone of knowledge creation and transfer theory, is the SECI model introduced by Nonaka and Takeuchi (1995). The authors distinguished between explicit knowledge (formal, codified knowledge) and tacit knowledge (knowledge in the minds of people), and drew attention to the way Western firms tend to focus too much on the former. They proposed four ways that knowledge types can be combined and converted, showing how knowledge is shared and created in the organisation: socialisation, externalisation, combination and internalisation (SECI). The process of socialisation occurs when tacit knowledge is passed on through practice, guidance, imitation and observation to create new tacit knowledge through shared experience, which also denotes the presence of a mutually agreed activity where individuals or groups of people interact in a uniform environment (Martín-de-Castro et al., 2008; Nonaka et al., 2000). Externalisation occurs when tacit knowledge is converted into explicit knowledge, i.e. codified into documents, manuals, etc. so that it can spread more easily through the organisation. This is particularly difficult since tacit knowledge can be virtually impossible to codify. Combination refers to the simplest form of knowledge creation/conversion, where codified knowledge sources (e.g. documents) are combined to create new knowledge. Lastly, internalisation describes the process of converting explicit into tacit knowledge, where a person's existing tacit knowledge is modified and extended by internalising knowledge as explicit sources are used and learned in practice (Nonaka \& Takeuchi, 1995). The knowledge creation process is widely acknowledged as a prominent vehicle for innovation through the application of novel ideas (Swan \& Newell, 2000). From this notion, both tacit knowledge and explicit knowledge are harmonised and (new) knowledge is created through a continuous dialogue between the two knowledge types (Nonaka, 1994). 
Taking the product view of KM, it is useful to gain an understanding of different types of relevant knowledge in PM settings. Based on qualitative research, Reich (2007) has identified four knowledge categories that are vital to the success of projects: process knowledge, domain knowledge, institutional knowledge and cultural knowledge. Process knowledge refers to knowledge that the project team and sponsors have about the project structure, methodology, tasks and timeframes. It allows a team to self-organise, since the team knows the outputs required and the time frames and can, if empowered, decide how the work should best be accomplished (Reich, 2007). Domain knowledge is knowledge about the environment or context within which the project operates. It includes the knowledge of the industry, firm, technologies, processes, business, products, current situation, problems/opportunities, risks and potential solutions (Reich, 2007). Institutional knowledge is a mix of history, power structure and values of the organisation (Reich, 2007). Cultural knowledge ties in with institutional knowledge and considers the cultural characteristics and backgrounds of the project team so as to understand how to manage IT staff (Reich, 2007).

The theoretical models and frameworks introduced in this section informed the design of the questionnaires used in this research as well as the structure of parent and child nodes for the analysis of the interview data (see section 3).

\subsection{Knowledge management in project environments}

$\mathrm{KM}$ and PM are two very distinct areas of study and a vast volume of publications exist across each domain. Although PM consists of knowledge-intensive activities, the majority of the literature focuses on the project manager while the study of KM in project environments only attracts a modest coverage (Brookes et al., 2006; Love et al., 2005).

In more recent times, several scholars have progressed towards bridging the gap between KM and PM, exploring diverse fields such as situated learning (Sense, 2007), post project reviews (Rezania \& Lingham, 2009) and issues in managing knowledge across project-based organisations (d'Armagnac, 2014). The link between KM and PM is often represented as KM in project environments (Hanisch et al., 2009; Koskinen \& Pihlanto, 2008; Lytras \& Pouloudi, 2003; Polyaninova, 2011; Pretorius \& Steyn, 2005).

Lessons learned are key project experiences that have relevance for future projects (Schindler \& Eppler, 2003). In their case study of an engineering consulting organisation, Owen and Burstein (2005) acknowledged that lessons learned from previous projects were applied at project planning phases to avoid obvious mistakes, which was usually done through informal methods. It was also noted that lessons learned processes were seen as a form of knowledge creation, the first step sequence in the KM life cycle. Polyaninova (2011) develops this further and suggests that project knowledge is generated from two sources - internal and external. Internal sources include risk logs, lessons learned and experience while external sources include seminars, benchmarking and competitor analysis.

\subsection{Knowledge and the project manager}

The role of the project manager has been discussed by various authors (Gaddis, 1959; Morris et al., 2006) and the demand for such practitioners is growing. For example, according to the PMI (2013b), "between 2010 and 2020, 15.7 million new project management roles will be added globally across seven project intensive industries" (p. 2). These include Manufacturing, Business Services, Finance and Insurance, Oil and Gas, Information Services, Constructions and Utilities. However, there are significant voices opining that project managers fall into the profession by chance or coincidence (Darrell et al., 2010; Pinto \& Kharbanda, 1995). This is further amplified by Richardson et al. (2015) who argue "...professional project managers do not intend to be project managers but 'fall into' the profession” (p.1).

There is a growing body of empirical work dedicated to focusing on the project manager as the theme or the unit of analysis. Such research focuses on the perspectives and opinions of the project manager as they relate to the topic of investigation. Geraldi et al. (2010) explored the enabling conditions that support a project manager's ability to cope with unexpected events 
and questioned “...what organisational foundations are relevant to respond to unexpected events successfully?” (p. 548). Creasy and Anantatmula (2013) focused on personality traits and dimensions of project managers and how they impact project success. Sewchurran and Barron (2008) examined the relationship between project managers and project sponsors in the delivery of IT projects. Several other scholars have examined the project manager as part of their analysis towards understanding cognitive decision making (Esa et al., 2014), competencies (Hanif \& Tariq, 2014) and leadership (Geoghegan \& Dulewicz, 2008). There is however, a lack of enquiry examining the role of and the relationship between knowledge and the project manager. Therefore, the following research question underpins this study:

\section{How do ICT project managers manage project knowledge in the public sector?}

A detailed description of the research methodology used to address this research question is presented in the next section followed by a discussion of the results.

\section{Methodology}

A qualitative method was used to pursue the objectives of this investigation as it is aligned with the interpretivist paradigm (Weber, 2004). The interpretivist paradigm draws on meanings from social context (Rowlands, 2005), in this case from the perceptions of ICT project managers across several departments within the VPS. It is designed to capture and interpret meanings and understandings, exploring how and why a particular phenomenon occurs in its contemporary context in real-world setting (Weber, 2004).

Case study research often follows the interpretive custom of exploration whereby the phenomenon is explored through the lens of participants (Cohen et al., 2007). Shavelson and Towne (2002) note that the case study approach is applicable when your research tackles questions of a descriptive nature such as what happens (or happened) or explanatory questions such as how or why something occurs (or occurred), which aim to produce a first-hand understanding of the issue. Thus the case study approach allowed the researchers to explore empirical events and acquire data that provides insights from participants that would not otherwise be captured through other research methods.

An embedded case study design has been adopted for the research (Yin, 2009). The overarching case study is the VPS, while each project manager represented their respective departments within the VPS and thus served as embedded sub-cases within the overarching case (Yin, 2009). In this design the project manager is the unit of analysis. This design supported a detailed level of enquiry and provided opportunities for extensive analysis.

A semi-structured interview process was used since questions were based on existing theoretical models. The design of the questionnaire was informed by the KM life cycle models presented in section 2.2. with the components knowledge creation, knowledge capture and storage, knowledge sharing and knowledge application/reuse. Parent nodes such as knowledge required and knowledge creation were filtered through Reich's (2007) knowledge types required in IT projects and Nonaka and Takeuchi's (1995) SECI model, respectively (cf. section 2.2.). Such efforts were intended to enrich these existing models and further the understanding of the role of KM in PM. Open-ended questions were used to elicit information from respondents allowing for further dialogue and discussions to be generated (Chen et al., 1995).

The project manager was chosen as the subject of enquiry (or unit of analysis) for reasons elaborated on in the background section of the paper. As the research question suggests, there is a predetermined demographic target. For consistency, the study established a baseline set of standards in relation to the experience levels of participants. To support intra-case comparison and analysis it was important that project managers had managed similar projects in terms of budget and/or scope. In addition, it was important that participants have had some experience in project management that they could reflect on when responding to questions. Therefore, participants selected for the study had managed ICT projects with a minimum budget of $\$ 100,000$, a project duration of at least one year (in any project managed at the time of 
interview), were currently serving as an employee within their respective departments and had been employed with the VPS for at least two years.

Two project managers were shortlisted and interviewed across each VPS department, totalling a sample size of 14 project managers. The sample size is consistent within the single exploratory case study approach, as is evidenced by other research with similar subjects of enquiry (Blackburn, 2002; McHugh \& Hogan, 2011; Worthy, 2012). Interviews were transcribed to facilitate data analysis via the NVIVO software package. Transcriptions were analysed via a coding in detail approach whereby codes were grouped into tree nodes (Bazeley, 2007, p. 69) informed by the KM models presented in section 2.2. This allowed for relationships amongst themes and issues to be assessed and for emergent phenomena to be examined.

\section{Results}

This section presents the data and related patterns emerging from the interviews. Table 1 below represents the initial nodes (informed by the KM models highlighted in section 2.2.) that were used to classify interview data. The remainder of this section elaborates on the findings from the interviews.

\begin{tabular}{|l|l|c|}
\hline \multicolumn{1}{|c|}{ Parent Node } & \multicolumn{1}{c|}{ Child Nodes } & \multicolumn{1}{c|}{$\begin{array}{c}\text { Number of } \\
\text { References }\end{array}$} \\
\hline \multirow{4}{*}{ Knowledge required } & Process knowledge & 10 \\
\cline { 2 - 3 } & Institutional knowledge & 5 \\
\cline { 2 - 3 } & Domain knowledge & 4 \\
\cline { 2 - 3 } & Cultural knowledge & 3 \\
\hline \multirow{4}{*}{$\begin{array}{l}\text { Knowledge creation } \\
\text { storage }\end{array}$} & Socialisation & 13 \\
\cline { 2 - 3 } & Internalisation & 4 \\
\cline { 2 - 3 } & Combination & 3 \\
\cline { 2 - 3 } & Externalisation & 2 \\
\hline \multirow{4}{*}{ Knowledge sharing } & Procedural & 11 \\
\cline { 2 - 3 } & Electronic systems & 10 \\
\hline \multirow{4}{*}{$\begin{array}{l}\text { Knowledge application and } \\
\text { reuse }\end{array}$} & Informal & 10 \\
\cline { 2 - 3 } & Agile & 6 \\
\cline { 2 - 3 } & Project artefacts & 6 \\
\cline { 2 - 3 } & Social media & 3 \\
\cline { 2 - 3 } & Pessons learned & 10 \\
\hline \multirow{2}{*}{ Personal experience } & 4 \\
\hline
\end{tabular}

Table 1: Classification of interview data against nodes/themes informed by KM models

\subsection{Knowledge required}

During the interview, participants were asked what types of knowledge they needed to successfully manage projects. Their responses were categorised using Reich's (2007) types of knowledge. References in relation to knowledge under the process knowledge category were made ten times, whilst institutional knowledge was mentioned five times, domain knowledge four times and cultural knowledge was referred to only three times, respectively. Interestingly, exploration of data provided evidence that 10 of the 14 participants referenced more than one knowledge type required for their project. However, no participant referenced more than two of Reich's (2007) four project knowledge types. 


\section{Theme 1: Process knowledge}

It was clear that the majority of the participants emphasised the need for process knowledge. Two participants specifically highlighted the need for a business case, as one suggested "The business case, for a start, or anything that's remotely close that tells me about the core elements about the projects" PM13.

\subsection{Knowledge creation}

Participants were asked how they created the knowledge required for managing projects. Results were classified against four nodes based on the SECI model of knowledge creation (cf. section 2.2.): internalisation, combination, externalisation and socialisation. Very few responses highlighted internalisation (4), combination (3) or externalisation (2) as a preferred knowledge creation approach. The vast majority, 13 participants, indicated that they adopted socialisation to create knowledge.

\section{Theme 2: Socialisation}

The socialisation process is achieved through a variety of techniques including workshops, training programs, (informal) meetings and the like. It was discovered that although some participants engaged in various forms of knowledge creation (i.e. internalisation, combination and externalisation), the majority most often employed the socialisation process to create new knowledge within their projects as illustrated by PM1:

PM1 "I feel it's important to talk to various people and have that connection and conversation with project stakeholders...especially those who are experts, which helps gather vital information to support my project. With that social interaction...that face-to-face interaction, I think it's invaluable, it helps me identify the knowledge gaps that exist within my everyday projects and I'm able to bring in new perspectives, new dynamics into my projects".

Interviews also demonstrated participants felt that they found this process to be the easiest and most efficient way to create knowledge for their projects. They alluded to the fact that emailing, telephoning or other methods of communication within their departments "slowed down" their knowledge creation capabilities, and thus their efforts were focused on socialisation. One participant (PM6) further justified this position as it allowed them to uncover knowledge that would not otherwise be captured through other forms of knowledge creation:

PM6 "I feel face-to-face meetings are much better because I feel that you pick up the extra dimension and pick up cues on people's voices, and what the severity levels are, if they have the confidence in their ability to solve problems and deal with issues they have. You know, I can have that ability to try to read between the lines that you would not normally get when dealing with emails or telephone conversations. So there's that extra dimension added when, that social complexity you have, that face-to-face interaction and meeting people as opposed to non-face-to-face interaction".

\subsection{Knowledge capture and storage}

Interviewees were asked to discuss how they captured the knowledge required to manage projects. Results were classified into two main themes: procedural and electronic systems with 11 and 10 references, respectively.

\section{Theme 3: Electronic systems and procedural methods}

Participants adopted a combination of electronic systems accompanied by either a departmental or (project) methodical process to categorise and store project knowledge. A large proportion of participants confirmed the existence of knowledge management systems and exploited such tools as required to store specific project knowledge. Of the participants who confirmed the usage of such systems, namely SharePoint and TRIM, most agreed that according to the best of their knowledge, there were no 'official' KM systems or a KM standard that was endorsed by their department or the VPS. However, participants indicated that they 
were highly encouraged to adopt the system (TRIM) and undergo training and development to improve user experience and project efficiency:

PM10 "In our department, we have to have a four hour introduction before you get access to TRIM and every single thing that you do is stored in TRIM. So you have to do this course literally the first day you start. It's very structured and much organised in that respect. There are documents and templates that are accessible through TRIM and I use quite to benefit my project. I also encourage my project team to use it as well. Yet, there is not a strict process or compliance standards that tell us project managers...you know...you are required to use this for all your projects and if you don't, then there will be consequences. So long as you stick to the known protocols within the department and follow a project methodology, you should be fine".

Participants stored project information into their dedicated network drives. Each of the participants confirmed that specific network drives were set up for project teams before projects even commenced. The participants would then create project folders and files that were consistent with a project methodology. For example, one of the participants would use a PRINCE2 approach as a guide to systematically set up and structure the project in their respective network drives. This includes folders such as pre-project, initiation, delivery/control and closing a project.

\subsection{Knowledge sharing}

\section{Theme 4: Informal structures}

An analysis of how participants engaged in sharing knowledge within their projects revealed an overwhelming consensus towards the adoption of the socialisation process. Some participants would create informal knowledge sharing structures of their own accord in addition to leveraging various social events or activities outside formal processes within their departments, as was the case of PM2:

PM2 "I find the best way to knowledge transfer or knowledge sharing is through an informal setting. I'd tried doing it as a lecture series or like a lunch session or something like that. And it really depends on people's personality types and how they operate. I find the best way to knowledge sharing...I love Melbourne and I enjoy my coffee and I'll have a chat. I have two coffees a day and I'll say "look let's go for a coffee and have a quick chat", where you're just waiting for things just so that's a little bit of transfer or sharing in that sort of instance. And it depends on the type of resource. I am an extrovert, so I find that doing things at a coffee shop or something like that with fellow extroverts is the best way to do transfer. If I am dealing with highly technical staff or subject matter experts, they tend to be very introverted so they really shut down in that sort of environment so it's really formal and having a formal meeting. For example, it'll be a one-on-one meeting, you know going through a structured agenda, with technical diagrams, and so I find that to be the best way in terms of sharing knowledge".

The phenomenon of using informal settings to share project knowledge seemed to be the dominant method. For most project managers, the idea of sharing project knowledge in an environment outside the "four walls" orchestrated by their departments brought about a degree of either establishing or enhancing an open and honest relationship within the project team.

PM2 "this [informal knowledge sharing] I'm much more comfortable with...certainly has its merits and beats traditional meetings. I get what I need or near to what I need, avoid potential issues and most of all avoid politics".

It was further emphasised that the participants would generally find the need to adopt this method to bring about team collegiality within their projects, extract meaningful information that would not otherwise be captured through formal means and efficiently solve project issues with suppliers and other project stakeholders. 


\section{Theme 5: Using agile techniques to facilitate knowledge sharing}

Agile PM techniques draw on the philosophy of the Agile Manifesto which values "individuals and interactions over processes and tools, working software over comprehensive documentation, customer collaboration over contract negotiation [and] responding to change over following a plan" (Beck et al., 2001). The results of this study suggested that participants relied on using agile techniques to facilitate the knowledge sharing process within the project team. PM12 suggested this approach generated a drive to share knowledge as the environment encouraged the project team to organically discuss technical issues including project integration and inter-dependencies, raise questions, resolve problems, provide feedback, facilitate team collaboration, build trust and foster new relationships.

PM12 "Well we have a lot of "stand ups". And this is part of the agile movement where the project team has a time boxed meeting between 5 to 15 minutes for a quick status update. We stand up to keep the meeting short every morning. The team asks for clarifications and makes brief statements about the project's progress, such as "Let's discuss this more after the meeting", so we avoid full-fledged discussions. The team leader asks if anyone else has anything to share and this is where the knowledge sharing really flourishes. So this is great for knowledge sharing and always works well. Other approaches include your basic communication mediums - telephone, emails and meetings etcetera.

PM8 "The key training there for us is to learn to communicate in that agile/Scrum sort of way - stand up meetings, sprint planning and sprint reviews and all that sort of thing. That is a much more effective way of communicating the project than through a PRINCE2 way, which is just documentation".

The free-flowing casual environment seems to yield a positive atmosphere for project managers and their teams, which demonstrated a level of equality, freedom of expression (including opinions) and allowing immediate access to members of the project team that would not otherwise be as approachable in traditional formal office structures. It was further revealed that knowledge sharing (within an agile environment) went beyond the dynamics of the project team and towards a tacit build up within clients/customers through face-to-face conversations during iterations. Participants expressed that having this freedom meant they were able to work outside the constraints of formal structures that would impede on their ability to roam and perform their duties as a project manager and tackle the scope of the project. They further voiced that removing the hurdles of documentation and traditional processes meant they were generally able to interact with other project members including business analysts, developers and testers. All in all, it was apparent that the agile approach played a pivotal role in the success of facilitating knowledge sharing as perceived by the participants and further allowed project managers to occupy roles within the project team.

\section{Theme 6: Project artefacts}

Another form of knowledge sharing within the project team was the use of project artefacts, namely project documentation. Participants described that they would circulate project documents or materials such as technical diagrams, business/process mapping, project plans, status reports and risk and issues registers to relevant stakeholders to share knowledge about their projects. The frequency of project artefact circulation differed depending on the nature of the project and the applied PM framework. The project artefacts were used to examine the health and status of the overall project, determine operational quality, confirm progress, reiterate constraints and dependencies and identify risks and issues. An emailing system was used as a key channel to transfer and share project documentation. This allowed the team to review, critique and update relevant information throughout the duration of the project.

\section{Theme 7: Social media}

Data provided evidence that there was to some extent continuous online knowledge sharing within projects. Participants reported 'Yammer' as the vehicle for collaboration, which was sometimes used with the stakeholders. In other words, it was not exclusively used for the 
project team but was available to other colleagues including senior users, suppliers, product owners, suppliers and vendors. As PM12 put it, "Depending on the piece of work, I am actually using Yammer at the moment for collaboration stuff with an external supplier and that's the easiest way to share information, it's consistent and handy". Further, data collected from interviews suggested that colleagues, including management, endorsed the usage of such products across projects. This platform did bring about a number of advantages to the project such as allowing users to share live information (including creating, editing and evaluating documents), requesting support, removing everyday obstacles such as organising meetings, co-ordinating work and a whole host of activities from work or in a remote setting.

\subsection{Knowledge application and reuse}

\section{Theme 8: Lessons learned}

A common strategy to apply and reuse knowledge from one project to another was the utilisation of a lessons learned process. This approach was widely practiced by the participants who saw this method as an effective medium to carry valuable knowledge for reuse. Participants indicated that the lessons learned process was a valued activity and was seen as an integral part of propagating effective methods throughout projects by sharing and reusing knowledge.

Data from the interviews also indicated that there was not one single guiding principle, method or practice according to which the lessons learned process was conducted. At times, the process was done informally at the end of the project where participants drew on their own experiences from past projects or organisations and created their own process for collecting, storing and disseminating the lessons. Participants would use existing templates either downloaded from their respective department's records management systems or by simply browsing the intranet. To do this, participants would follow systematic steps where they would identify and document what worked well and what needed improvement, generate a case for methods of improvement and ensure the material was archived as required by departmental standards.

Other forms of lessons learned activities included post project reviews such as face-to-face meetings. This was considered to be a more formal approach to lessons learned as it was controlled or monitored by a nominated facilitator. One of the participants stated that they would implement an agile technique to documenting lessons learned. Dubbed "Retrospective", project team members would meet at the end of each iteration (including after the completion of the project) and reflect/deliberate on what went well, what didn't and what could be improved. This approach allowed project managers to capture vital discussion points for future implementation.

When probed about what mechanisms exist or how the organisation supported the lessons learned process, participants unanimously agreed that more could be done from "upper chambers" of the department. For example, the lessons learned process should be made consistent and compulsory for every project and the PMO should play a more collegial role throughout such activities. Further, the lack of time available to undertake capturing lessons learned seemed to be a major hurdle for participants. Although they unanimously agreed on its importance, they felt that if they had more time overall, they would be able to spend more quality time on the lessons learned process. One participant expressed that sometimes it is considered a "dump and run exercise" due to the need to move on to other projects. Another challenge participants expressed was the notion of questioning or not relying on the originator of documents relating to lessons learned or post implementation reviews.

"Meaning" and "background" were the most frequently used words to describe how lessons learned were not readily understood within their context. In-depth narratives and contextual analysis were left out from most lessons learned documents. Thus, many experienced difficulties in trying to make use of and apply such knowledge to their current or future projects. Different circumstances and environments made it even more difficult to give meaning and usage. Participants sensed that they had to play "dodge-ball" in order to avoid "responsibility" and damage "reputation" because there was a high risk that their "voice" would 
not be heard. For example, “...in the past there has been plenty of covering up and not enough owning up" (PM4). However, this did not stop participants in documenting their project failures when it came to lessons learned. Participants tended to focus on questioning information arising from lessons learned, post implementation reviews and the like.

Lastly, locating or having access to lessons learned proved to be another challenge for the participants. Few recounted that they faced some difficulty locating the large database of documents and others mentioned that such documents were not made available to them. Those who reported having access issues agreed that much more could be done in either making relevant lessons learned available to them or providing a better database management system for retrieval and usage.

\section{Theme 9: Personal experience}

To a lesser extent, interviews demonstrated that participants' prior experiences lead them to reuse that knowledge. For example, the knowledge gained from previous projects, whether positive or negative, was applied to future projects. In other words, as a result of a series of events, behaviour was modified or new skills were acquired, which were then (tacitly) transported to new projects and applied in practice. Participants further indicated that not all knowledge could be captured and put on paper and successively transferred to other projects “... my 15 years of project experience in the public sector can't be expressed on paper...experience is what counts and managing project after project and learning what I've done in the past allows me to manage them [projects] more effectively" (PM7). Those who relied on personal experiences as an effective means to apply or reuse knowledge agreed that this brought about several benefits to new projects that would not otherwise be realised from other means.

\section{Discussion}

This section introduces an analysis of the research findings in relation to the existing literature. It examines what the discoveries mean in light of the current theoretical body of knowledge and highlights practical implications arising from the analysis.

\subsection{Knowledge required}

Classification of project manager responses related to the knowledge they require to manage their projects was made against Reich's (2007) model of the four knowledge types in IT projects. Almost all respondents indicated they needed process knowledge. Less than half of the respondents indicated that institutional, domain and cultural knowledge were required.

When probed for examples of process knowledge, many identified the business case as a critical document. The business case justifies the project and guides the development of early project planning (Kloppenberg, 2012); it helps stakeholders to determine if the project is feasible for the organisation (Axelos, 2009). Flawed business cases can lead to project failure (Whittaker, 1999) so a complete and accurate business case is essential for project managers to properly plan their projects (Axelos, 2009; Kloppenberg, 2012).

\subsection{Knowledge creation}

Results from the investigation affirmed the importance of the socialisation process. Knowledge creation relied on personal networks as participants would leverage a number of social activities and events including workshops, professional training and in particular, the use of informal meetings with colleagues. Informal approaches, which were also predominantly adopted for knowledge sharing (see knowledge sharing section 4.4.), were found to be the preferred method in the creation of knowledge as it allowed participants to bring in new perspectives to their projects; beyond what they would normally unearth through the scanning of random project documents. The concept of creating knowledge through non face-to-face interaction such as emailing and telephoning, although present and embraced, appeared not to be the favoured method, as it did not offer effective and immediate solutions to the required problem or question. However, Kao et al. (2011) argued that socialisation alone does not 
necessarily create knowledge. Rather, when combination and internalisation are executed and knowledge is internalised (i.e. put into action), knowledge can be generated.

\subsection{Knowledge capture and storage}

It was recognised that departments presented participants with relevant tools to be able to store project knowledge, and the process of capturing knowledge appeared to be tactical and systematic. These approaches resonate with Dougherty (2004), who suggested “...capturing it [knowledge] requires the practices themselves to be organised somehow" (p. 35). Additionally, participants often relied on IT as a tool to structure project information conforming to a strategy or a particular method. For example, the PRINCE2 method was used to set up project files and make knowledge explicit (i.e. tangible) for project use. In KM terms, this process is closely tied to the codification process whereby once relevant knowledge is captured, content is categorised in a systematic manner (Dalkir, 2005) and is accessible for further use (Almeida \& Soares, 2014; Boh, 2005) - an activity that was practiced in this study. From this perspective, Boh (2005) argues that once knowledge is codified in various artefacts, they can be recognised as important means for knowledge sharing. Moreover, to a lesser extent, the departmental electronic databases or record management systems were also used for knowledge capture and storage. Making use of such tools provides several benefits to the accessibility and reusing of knowledge (Kivrak et al., 2008).

The literature linking IT to knowledge capture is well established (Alavi \& Leidner, 2001; Lee \& Choi, 2003). It is considered to be a critical element in effectively managing intellectual capital (Chou, 2005; Dalkir, 2005; Egbu \& Botterill, 2002). It was identified that knowledge captured from previous projects was stored and reused for future projects (Kivrak et al., 2008). Such findings correspond with the results from this investigation. However, Gasik (2011) asserts that this process should be monitored at the organisational level to ensure appropriate classification, consistency and integrity of project knowledge. According to Dalkir (2005), it is simply more than making use of technology and he argues "...IT plays only a small part in ensuring that information is available to those who need it" (p. 78).

\subsection{Knowledge sharing}

Findings indicated that many informal meetings occurred in settings outside of the office in spaces such as nearby parks, cafés, lounges, in cars while travelling to project sites and even at home. However, it was also noted that specific meeting spaces were selected dependent on the type of information required. Davenport and Prusak (2000) noted that such locations were common, which also gave rise to a sense of mutual trust outside the boundaries of the organisation with collaboration from stakeholders such as customers and suppliers (Nonaka et al., 2000).

Participants enjoyed the idea of freely conversing with project team members through informal environments. According to Karlsen et al. (2011), the agile paradigm places less emphasis on project documentation and partially replaces it by informal interactions within and between project teams and stakeholders. This view along with those of Cockburn and Highsmith (2001), Chau and Maurer (2004), Dybå and Dingsøyr (2008), Boden et al. (2009) and Stettina et al. (2012) are consistent with the findings of this investigation.

A key factor that enabled participants to share knowledge was not only the establishment of a casual environment, but a set of workspaces that allowed speedy access to members of a project team. According to Santos et al. (2013), such a climate enables project teams to be conscious of emerging organisational matters, network with little effort and have a sense of purpose beyond their project team.

\subsection{Knowledge application and reuse}

Interviews revealed two main themes concerning the application and reuse of knowledge lessons learned and personal experience. Results uncovered two main approaches to lessons learned; formal and informal practices. This tallies with Jugdev (2012) who argues that lessons learned processes “...involve formal and informal practices” (p. 14) and occur in "...self- 
directed, collective and social ways" (p. 20). This is echoed by Owen et al. (2004) who postulate that this process is critical in the creation, transfer and reuse of knowledge for projects.

The results of this research build upon these findings, since participants took on the initiative with little assistance or direction, formulating their own practices to drive the lessons learned process. Moreover, it was determined that once lessons were captured at the end of the project, they were archived in a server or a department database and reused for forthcoming projects. Owen and Burstein (2005) opined that once project material is stored in such systems, the content needs to be maintained or updated to ensure it's relevant for future project use. Although the method of storing lessons learned was consistent with Owen and Burstein's (2005) proposition, little evidence was found of mechanisms that supported participants in updating the material once archived. Furthermore, while not practicing lessons learned at the end of a project is not uncommon, it does result in low quality outcomes, and a lack of cross project learning (Ajmal \& Koskinen, 2008; Pemsel \& Wiewiora, 2013).

The lack of time to capture lessons learned has been well documented in the literature (Carillo et al., 2004; Keegan \& Turner, 2001; Von Zedtwitz, 2002) and findings from this paper concur with literature across the PM and KM fields (Fadairo, 2016; Paranagamage et al., 2012; Pemsel \& Wiewiora, 2013; Shokri-Ghasabeh \& Chileshe, 2014).

One major factor was the presence of contemporaneous and new projects, which posed a barrier to spending quality time identifying and capturing lessons learned. Further efforts should focus on other factors that impede PM to capture lessons learned in these environments and pragmatic solutions should be made available for sustainable and long term competitiveness (Anbari et al., 2008).

\section{Conclusion}

ICT projects are temporal organisations accepted to be knowledge-intensive organisational forms that have to address complex, socio-technical business changes. To be successful, projects critically depend on utilising and creating the right mix of knowledge and experiences. Moreover, due to the temporal nature of projects, acquired knowledge and experiences can become hard to access and leverage in future projects if not handled properly by a suitable KM function. Thus, as a first step towards improving existing practices in future, it is essential to increase our understanding of how PM activities are currently supplemented by KM activities in practice. There is a particular gap of insight to date regarding public sector environments.

This paper presents the findings of a descriptive case study that examines how a cohort of ICT project managers in several departments of the VPS manage project knowledge. Several general conclusions may be drawn from the work, which has been presented in detail in the results and discussion sections of this paper. One particular theme stood out from the analysis of the interview data in the study, and that was the participants' preference for informal structures and face-to-face interactions/exchanges. This preference falls under the umbrella of the socialisation category of the SECI model and is best enabled by agile approaches to PM that shift the emphasis from formal codified project artefacts towards human interactions. Process knowledge turned out to be the most relevant type of knowledge in the project context in the VPS according to the participants. The importance of both personal experience and codified lessons learned was acknowledged by the interviewees. While both procedural methods and electronic systems (including enterprise social media) are actively being used in projects to facilitate capturing and sharing project artefacts.

The empirical research presented in this paper contributes to and extends the existing body of knowledge regarding the role of knowledge management in ICT project management contexts, an area that is currently characterised by a rather limited amount of prior research. One limitation of the research is the relatively small sample size of 14 ICT project managers across seven departments in a single case study of the VPS. Therefore, the findings of this study should be considered as a driver and starting point for further research. More empirical research is needed in order to further increase understanding of how knowledge is managed across the 
project life cycle and to derive actionable insights into how this process can be improved. Future work will seek to capture a broader sample of participants via a survey based on the findings presented in this paper. As part of a larger research program, the authors are also investigating the barriers to knowledge sharing that are commonly experienced in PM settings.

The results of this study make an academic contribution by adding to the empirical foundation of our knowledge about the topic area. They also contribute to practice by informing project managers and consultants carrying ICT projects in public sector environments.

\section{References}

Abdul Rahman, H., Yahya, I. A., Beravi, M. A. \& Wah, L. W. (2008) "Conceptual delay mitigation model using a project learning approach in practice", Construction Management and Economics, 26(1): 15-27.

Ajmal, M. M. \& Koskinen, K. U. (2008) "Knowledge transfer in project-based organizations: an organizational culture perspective", Project Management Journal of Information Science, 39(1): 7-15.

Alavi, M. \& Leidner, D. E. (2001) "Knowledge management and knowledge management systems: conceptual foundations and research issues", MIS Quarterly, 25(1): 107-136.

Almeida, M. V. \& Soares, A. L. (2014) "Knowledge sharing in project-based organizations: overcoming the informational limbo", International Journal of Information Management, 34(6): 770-779.

Amayah, A. T. (2013) "Determinants of knowledge sharing in a public sector organization", Journal of Knowledge Management, 17(3): 454-471.

Anbari, F. T., Carayannis, E. G. \& Voetsch, R. J. (2008) "Post-project reviews as a key project management competence", Technovation, 28(1): 633-643.

Argote, L. \& Ingram, P. (2000) "Knowledge transfer: a basis for competitive advantage in firms", Organizational Behavior and Human Decision Processes, 82(1): 150-169.

Aurum, A., Daneshgar, F. \& Ward, J. (2008) "Investigating Knowledge Management practices in software development organisations-An Australian experience", Information and Software Technology, 5o(6): 511-533.

Axelos. (2009) Managing successful projects with PRINCE2, The Stationery Office, Belfast, Northern Ireland.

Bazeley, P. (2007) Qualitative analysis with NVivo, Sage, California, USA.

Beck, K., Beedle, M., van Bennekum, A., Cockburn, A., Cunningham, W., Fowler, M., Grenning, J., Highsmith, J., Hunt, A., Jeffries, R., Kern, J., Marick, B., Martin, R. C., Mellor, S., Schwaber, K., Sutherland, J. \& Thomas, D. (2001) Manifesto for Agile Software Development. Available at: http://www.agilemanifesto.org/ [Accessed 30 August 2016]

Blackburn, S. (2002) "The project manager and the project-network", International Journal of Project Management, 2O(3): 199-204.

Blumentritt, R. \& Johnston, R. (1999) "Towards a strategy for knowledge management", Technology Analysis \& Strategic Management, 11(3): 287-300.

Boateng, H. \& Agyemang, F. G. (2014) "A qualitative insight into key determinants of knowledge sharing in a public sector institution in Ghana", Information Development(April 17, 2014): 1-10.

Boden, A., Avram, G., Bannon, L. \& Wulf, V. (2009) Knowledge management in distributed software development teams does culture matter?, Paper presented at the Fourth IEEE International Conference on Global Software Engineering, Limerick, Ireland.

Boh, W. F. (2005) Reuse of intellectual capital from repositories: A mixed methods study, Paper presented at the Academy of Management Meeting, Honolulu, Hawaii. 
Brookes, N., Morton, S., Dainty, A. \& Burns, N. (2006) "Social processes, patterns and practices and project knowledge management: a theoretical framework and an empirical investigation", International Journal of Project Management, 24(6): 474-482.

Brouwer, G. (2011). Own motion investigation into ICT-enabled projects: Melbourne: Victorian Ombudsman, Victorian Government Printer.

Cadle, J. \& Yeates, D. (2004) Project Management for Information Systems, Pearson Education.

Carillo, P., Robinson, H., Al-Ghassani, A. \& Anumba, C. (2004) "Knowledge management in UK construction: strategies, resources and barriers", Project Management Journal, 35: 46-56.

Chau, T. \& Maurer, F. (2004). Knowledge sharing in agile software teams. In M. M. Richter \& W. Lensk (Eds.), Logic versus approximation (pp. 173-183). Berlin: Springer.

Chen, V., Pearce, W. B. \& Leeds-Hurwitz, W. (1995) "Even if a thing of beauty, can a case study be a joy forever", Social Approaches to Communication: 135-154.

Chou, S.-W. (2005) "Knowledge creation: absorptive capacity, organizational mechanisms, and knowledge storage/retrieval capabilities", Journal of Information Science, 31(6): 453-465.

Cockburn, A. \& Highsmith, J. (2001) "Agile software development, the people factor", Computer, 34(11): 131-133.

Cohen, L., Manion, L. \& Morrison, K. (2007) Research methods in education (6th ed.), Routledge/Taylor \& Francis Group, New York, NY, US.

Cong, X. \& Pandya, K. V. (2003) "Issues of knowledge management in the public sector", Electronic Journal of Knowledge Management, 1(2): 25-33.

Coyte, R., Ricceri, F. \& Guthrie, J. (2012) "The management of knowledge resources in SMEs: an Australian case study", Journal of Knowledge Management, 16(5): 789-807.

Creasy, T. \& Anantatmula, V. S. (2013) "From every direction-how personality traits and dimensions of project managers can conceptually affect project success", Project Management Journal, 44(6): 36-51.

d'Armagnac, S. (2015) "Issues in the management of embedded knowledge in project-based organizations: the project actor's role", Knowledge Management Research \& Practice, 13(4): 446-462.

Dalkir, K. (2005) Knowledge management in theory and practice, Elsevier ButterworthHeinemann, Burlington.

Darrell, V., Baccarini, D. \& Love, P. E. D. (2010) "Demystifying the folklore of the accidental project manager in the public sector", Project Management Journal, 41(5): 56-63.

Davenport, T. \& Prusak, L. (2000) Working Knowledge, (2nd ed.), Harvard Business Press, USA.

Dougherty, D. (2004) "Organizing practices in services: Capturing practice-based knowledge for innovation", Strategic Organization, 2(1): 35-64.

Downes, T. V. (2014) An evaluation of knowledge management practices in nonprofit community services organisations in Australia. (Doctor of Business Administration), Southern Cross University, Lismore, NSW.

Dybå, T. \& Dingsøyr, T. (2008) "Empirical studies of agile software development: A systematic review", Information and Software Technology, 5o(9): 833-859.

Egbu, C. O. \& Botterill, C. (2002) "Information technologies for knowledge management: their usage and effectiveness", ITcon, 7: 125-137. 
Esa, M., Alias, A. \& Abdul Samad, Z. (2014) "Project managers' cognitive style in decision making: a perspective from construction industry", International Journal of Psychological Studies, 6(2): 65-73.

Evans, M. \& Ali, N. (2013) Bridging knowledge management life cycle theory and practice, Paper presented at the International Conference on Intellectual Capital, Knowledge Management and Organisational Learning, Washington DC, USA.

Evans, M., Dalkir, K. \& Bidian, C. (2014) "A holistic view of the knowledge life cycle: the knowledge management cycle (KMC) model", Electronic Journal of Knowledge Management, 12(2): 85-97.

Fadairo, O. (2016) benefits of conducting postproject reviews to capture lessons learned. (Doctor of Business Administration), Walden University, Minneapolis, USA.

Gaddis, P. O. (1959) The project manager, Harvard University.

Gasik, S. (2011) "A model of project knowledge management", Project Management Journal, 42(3): 23-44.

Geoghegan, L. \& Dulewicz, V. (2008) "Do project managers' leadership competencies contribute to project success?", Project Management Journal, 39(4): 58-67.

Geraldi, J. G., Lee-Kelley, L. \& Kutsch, E. (2010) "The Titanic sunk, so what? Project manager response to unexpected events", International Journal of Project Management, 28(6): 547-558.

Grant, K. \& Grant, C. (2008) The knowledge management capabilities of the major Canadian financial institutions, Paper presented at the The International Conference on Knowledge Management.

Hanif, A. \& Tariq, S. (2014) An evaluation of personal and interpersonal competencies of project managers, Paper presented at the 2014 International Conference on Emerging Technologies (ICET), Islamabad, Pakistan.

Hanisch, B., Lindner, F., Mueller, A. \& Wald, A. (2009) "Knowledge management in project environments", Journal of Knowledge Management, 13(4): 148-160.

Ismail, W., Nor, K. \& Marjani, T. (2009) "The role of knowledge sharing practice in enhancing project success", Institute of Interdisciplinary Business Research, 1(7): 34-52.

Jugdev, K. (2012) "Learning from lessons learned: project management research program", American Journal of Economics and Business Administration, 4(1): 13-22.

Kao, S., Wu, C. \& Su, P. (2011) "Which mode is better for knowledge creation?", Management Decision, 49(7): 1037-1060.

Karagoz, Y., Korthaus, A., \& Augar, N. (2014) Barriers to Knowledge Sharing in ICT Project Environments. Paper presented at the 25th Australasian Conference on Information Systems, Auckland, New Zealand.

Karlsen, J. T., Hagman, L. \& Pedersen, T. (2011) "Intra-project transfer of knowledge in information systems development firms", Journal of Systems and Information Technology, 13(1): 66-80.

Keegan, A. \& Turner, J. R. (2001) "Quantity versus quality in project-based learning practices", Management Learning, 32(1): 77-98.

Khandelwal, V. K. \& Gottschalk, P. (2003) "Information technology support for interorganizational knowledge transfer: An empirical study of law firms in Norway and Australia", Information Resources Management Journal, 16(1): 14-23.

Kivrak, S., Arslan, G., Dikmen, I. \& Birgonul, M. T. (2008) "Capturing knowledge in construction projects: knowledge platform for contractors", Journal of Management in Engineering, 24(2): 87-95. 
Kloppenberg, T. J. (2012) Contemporary Project Management, (2nd ed.), South Western, Cengage Learning, Mason, $\mathrm{OH}$.

Koskinen, K. U. \& Pihlanto, P. (2008) Knowledge management in project-based companies, Palgrave Macmillan.

Lee, H. \& Choi, B. (2003) "Knowledge management enablers, processes, and organizational performance: an integrative view and empirical examination", Journal of Management Information Systems, 2O(1): 179-228.

Linger, H., Hasan, H. M. \& Burstein, F. (2007) "Integrating doing and thinking in a work context: an Australian knowledge management perspective", Scandinavian Journal of Information Systems, 19(1): 59-86.

Love, P. E., Fong, P. S.-W. \& Irani, Z. (2005) Management of knowledge in project environments, Routledge.

Lytras, M. D. \& Pouloudi, A. (2003) "Project management as a knowledge management primer: the learning infrastructure in knowledge-intensive organizations: projects as knowledge transformations and beyond", The Learning Organization, 1O(4): 237-250.

Maier, R., Haedrich, T. \& Peinl, R. (2005) Enterprise Knowledge Infrastructures, Springer, Berlin.

Mansingh, G., Osei-Bryson, K.-M. \& Reichgelt, H. (2014). Knowledge sharing in the health sector in Jamaica: the barriers and the enablers Knowledge Management for Development (pp. 199-213): Springer.

Maqsood, T., Finegan, A. \& Walker, D. (2006) "Applying project histories and project learning through knowledge management in an Australian construction company", The Learning Organization, 13(1): 80-95.

Martín-de-Castro, G., López-Sáez, P. \& Navas-López, J. E. (2008) "Processes of knowledge creation in knowledge-intensive firms: Empirical evidence from Boston's Route 128 and Spain", Technovation, 28(4): 222-230.

McHugh, O. \& Hogan, M. (2011) "Investigating the rationale for adopting an internationallyrecognised project management methodology in Ireland: the view of the project manager", International Journal of Project Management, 29(5): 637-646.

Mohammed, W. \& Jalal, A. (2011) "The influence of knowledge management system (KMS) on enhancing decision making process (DMP)", International Journal of Business and Management, 6(8): 216-229.

Morris, P. W., Jamieson, A. \& Shepherd, M. M. (2006) "Research updating the APM body of knowledge 4th edition", International Journal of Project Management, 24(6): 461-473.

Nonaka, I. (1994) "A dynamic theory of organizational knowledge creation", Organization Science, 5(1): 14-37.

Nonaka, I. \& Takeuchi, H. (1995) The knowledge-creating company: How Japanese companies create the dynamics of innovation, Oxford University Press.

Nonaka, I., Toyama, R. \& Konno, N. (2000) "SECI, ba and leadership: a unified model of dynamic knowledge creation", Long Range Planning, 33(1): 5-34.

Owen, J. \& Burstein, F. (2005). Where knowledge management resides within project management. In M. Jennex (Ed.), Case Studies in Knowledge Management (pp. 138154). Hershey, PA: Idea Group Publishing.

Owen, J., Burstein, F. \& Mitchell, S. (2004) "Knowledge reuse and transfer in a project management environment", Journal of Information Technology Case and Application Research, 6(4): 21-35. 
Paranagamage, P., Carrillo, P., Ruikar, K. \& Fuller, P. (2012) "Lessons learned practices in the UK construction sector: current practice and proposed improvements", Engineering Project Organization Journal, 2(4): 216-230.

Paulin, D. \& Suneson, K. (2015). Knowledge transfer, knowledge sharing and knowledge barriers-three blurry terms in KM. In K. Grant \& J. Dumay (Eds.), Leading Issues in Knowledge Management (Vol. 2, pp. 73-94).

Pemsel, S. \& Wiewiora, A. (2013) "Project management office a knowledge broker in projectbased organisations", International Journal of Project Management, 31(1): 31-42.

Pinto, J. K. \& Kharbanda, O. P. (1995) "Lessons for accidental profession", Business Horizons, 38(2): 41-50.

PMI. (2013a) A Guide to the Project Management Body of Knowledge (PMBOK® Guide), (5th ed.), Project Management Institute, Pennsylvania, USA.

PMI. (2013b) PMI's Industry Growth Forecast: Project Management Between $201 O+2020$. . Available at: http://www.pmi.org/ /media/PDF/BusinessSolutions/PMIProjectManagementSkillsGapReport.ashx [Accessed 12 July 2015]

PMI. (2015) PMI's Pulse of the Profession: Capturing the Value of Project Management Through Knowledge Transfer. Available at: http://www.pmi.org/ /media/PDF/learning/capturing-value-knowledge-transfer.ashx [Accessed 12 July 2015]

Polyaninova, T. (2011) "Knowledge management in a project environment: organisational CT and project influences", Vine, 41(3): 1-16.

Pretorius, C. \& Steyn, H. (2005) "Knowledge management in project environments", South African Journal of Business Management, 36(3): 41-50.

Reich, B. H. (2007) "Managing knowledge and learning in IT projects: a conceptual framework and guidelines for practice", Project Management Institute, 38(2): 5-17.

Renzl, B. (2006) "Trust in management and knowledge sharing: the mediating effects of fear and knowledge documentation", Omega, 36: 206-220.

Rezania, D. \& Lingham, T. (2009) "Towards a method to disseminate knowledge from the post project review", Knowledge Management Research \& Practice, 7(2): 172-177.

Richardson, T. M., Earnhardt, M. P. \& Marion, J. W. (2015) "Is project management still an accidental profession? A qualitative study of career trajectory", SAGE Open, 5(1): 1-10.

Rosacker, K. M. \& Rosacker, R. E. (2010) "Information technology project management within public sector organizations", Journal of Enterprise Information Management, 23(5): 587-594.

Rowlands, B. H. (2005) "Grounded in practice: Using interpretive research to build theory", The Electronic Journal of Business Research Methodology, 3(1): 81-92.

Sağsan, M. (2006) A new life cycle model for processing of knowledge management, Paper presented at the 2nd International Conference on Business, Management and Economics, Izmir, Turkey.

Sandhu, M. S., Jain, K. K. \& bte Ahmad, I. U. K. (2011) "Knowledge sharing among public sector employees: evidence from Malaysia", International Journal of Public Sector Management, 24(3): 206-226.

Santos, V., Goldman, A., Guerra, E., De Souza, C. \& Sharp, H. (2013) A pattern language for inter-team knowledge sharing in agile software development, Paper presented at the 20th Conference on Pattern Languages of Programs, Monticello, IL. 
Sarayreh, B., Mardawi, A. \& Dmour, R. (2012) "Comparative study: the Nonaka model of knowledge management", International Journal of Engineering and Advanced Technology, 1(6): 45-48.

Schindler, M. \& Eppler, M. J. (2003) "Harvesting project knowledge: a review of project learning methods and success factors", International Journal of Project Management, 21(3): 219-228.

Schwartz, D. (Ed.). (2005). Encyclopedia of Knowledge Management. Hershey, PA: IGI Global.

Seba, I., Rowley, J. \& Delbridge, R. (2012) "Knowledge sharing in the Dubai police force", Journal of Knowledge Management, 16(1): 114-128.

Sense, A. J. (2007) "Structuring the project environment for learning", International Journal of Project Management, 25(4): 405-412.

Sewchurran, K. \& Barron, M. (2008) "An investigation into successfully managing and sustaining the project sponsor-project manager relationship using soft systems methodology", Project Management Journal, 39(1): 56-68.

Shavelson, R. J. \& Towne, L. (Eds.). (2002). Scientific research in education. Washington DC, USA: National Academies Press.

Shokri-Ghasabeh, M. \& Chileshe, N. (2014) "Knowledge management: barriers to capturing lessons learned from Australian construction contractors perspective", Construction Innovation, 14(1): 108-134.

Soliman, F. (2000) "Application of knowledge management for hazard analysis in the Australian dairy industry", Journal of Knowledge Management, 4(4): 287-294.

Stettina, C. J., Heijstek, W. \& Fægri, T. E. (2012) Documentation work in agile teams: the role of documentation formalism in achieving a sustainable practice, Paper presented at the Agile Conference (AGILE), Dallas, Texas.

Swan, J. \& Newell, S. (2000) Linking knowledge management and innovation, Paper presented at the 8th European Conference on Information Systems, Vienna.

Turner, J. (2009). The handbook of project-based management: leading strategic change in organizations (Vol. 452): McGraw-Hill.

Von Zedtwitz, M. (2002) "Organizational learning through post-project reviews in R\&D", $R \& D$ Management, 32(3): 255-268.

Wallace, D. (2007) Knowledge management: historical and cross-disciplinary themes, (2nd ed.), Libraries Unlimited Inc, USA.

Wang, S. \& Noe, R. A. (2010) "Knowledge sharing: a review and directions for future research", Human Resource Management Review, 2O(2): 115-131.

Weber, R. (2004) "Editor's comments: the rhetoric of positivism versus interpretivism: a personal view", MIS Quarterly, 28(1): iii-xii.

Whittaker, B. (1999) "What went wrong? Unsuccessful information technology projects", Information Management \& Computer Security, $7(1):$ 23-30. doi: doi:10.1108/09685229910255160

Worthy, T. (2012) Knowledge sharing among a community of project managers: a descriptive case study examining the relationship between social structures and knowledge sharing among project managers in a global engineering firm. (Doctor of Education), The George Washington University, Ann Arbor, MI, USA.

Yao, L. J., Kam, T. H. Y. \& Chan, S. H. (2007) "Knowledge sharing in Asian public administration sector: the case of Hong Kong", Journal of Enterprise Information Management, 2O(1): 51-69. 
Yin, R. K. (2009) Case study research: design and methods, SAGE Publications.

Yusof, Z. M., Ismail, M. B., Ahmad, K. \& Yusof, M. M. (2012) "Knowledge sharing in the public sector in Malaysia a proposed holistic model", Information Development, 28(1): 43-54.

Zhang, M. J. (2007) "An empirical assessment of the performance impacts of IS support for knowledge transfer", International Journal of Knowledge Management, 3(1): 66-85.

Zhou, A. Z. (2004) "Managing knowledge strategically: a comparison of managers' perceptions between the private and public sector in Australia", Journal of Information and Knowledge Management, 3(3): 213-222.

Zhou, A. Z. \& Fink, D. (2003) "The intellectual capital web: a systematic linking of intellectual capital and knowledge management", Journal of Intellectual Capital, 4(1): 34-48.

Copyright: (C) 2016 Karagoz, Korthaus \& Augar. This is an open-access article distributed under the terms of the Creative Commons Attribution-NonCommercial 3.0 Australia License, which permits non-commercial use, distribution, and reproduction in any medium, provided the original author and AJIS are credited.

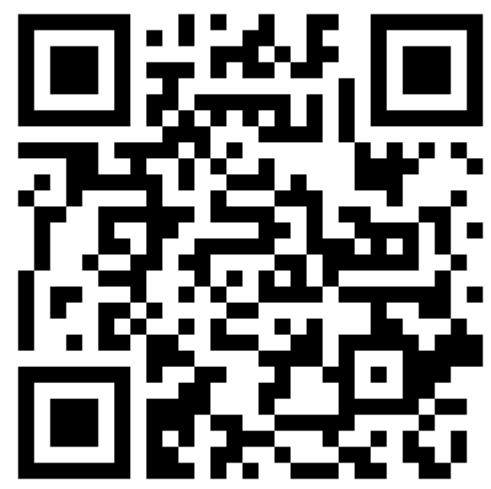

